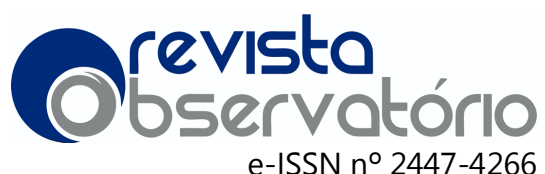

Vol. 6, n. 1, Janeiro-Março. 2020

\section{Tendências e desafios para a política de formação dos gestores: Uma análise interdisciplinar de educação intercultural no campo}

Trends and challenges for the policy of manager training: an interdisciplinary analysis of intercultural education in the rural area

Tendencias y desafíos de la política de formación directiva: Un análisis interdisciplinario de la educación intercultural en el campo

\section{Celenita Gualberto Pereira Bernieri}

Mestre em Sustentabilidade junto a Povos e Terras Tradicionais (UnB). Gestora Educacional na Secretaria Municipal de Educação de Dianópolis-TO. celegpb@gmail.com.

(1) 0000-0001-6437-1538

\section{Solange Aparecida Machado}

Mestranda em Educação (UFT). Professora da Unitins e da Universidade da Maturidade - UMA (Polo de Dianópolis), Tutora Presencial do Curso de Pedagogia UNOPAR.giovanadno@gmail.com.

(1) 0000-0002-8632-3139

Correspondência: Secretaria Mun. de Educação, Prefeitura Mun. de Dianópolis. Rua Diana Wolney, esquina com João Correia de Melo, Centro. 77300000 Dianópolis, TO - Brasil.
Recebido em: 01.06.2019.

Aceito em: 09.12.2019.

Publicado em: 03.01.2020.

\section{RESUMO}

A pesquisa apresenta pensamentos sobre determinadas tendências na formação dos gestores educacionais e as necessidades de inovação para buscar suprir as lacunas relacionadas ao ensino básico. Estas quais têm exigido sob o panorama da realidade característica de educação do campo: a construção das demandas na política da educação fundamental e suas perspectivas de transformações da própria gestão. Com a menção teórica metodológica de uma pesquisa bibliográfica e documental, buscou-se fundamentos históricos e filosóficos para o entrosamento das categorias trabalhadas e o foco empírico estabelecido em escolas estaduais da Regional de Dianópolis, para delimitar o campo da mesma, que segundo a abordagem, as alternativas têm sido de buscar efetivar ações de auto formação, simultaneamente às organização das práticas nas instituições de ensino. O que tem possibilitado um exercício parcial do instrumento curricular, ao contemplar uma educação que pense com as diversidades culturais e as relações étnico-raciais, buscando através de experiências e diálogos, apreciar e adotar conhecimentos comunitários com a valorização da subjetividade nos modos de cada comunidade, evidenciando-os no cotidiano escolar. A contradição entre as legislações e a marginalização educacional, evidencia a insuficiência na aplicabilidade de educação do campo, contudo, consiste destacar - se como maior desafio a urgência na reformulação da política de formação continuada dos gestores, propõe-se a transdisciplinar.

PALAVRAS-CHAVE: Formação de gestores; política pública; educação do campo; relações étnico-raciais. 


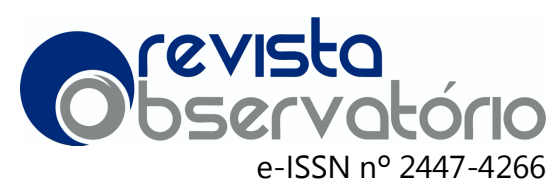

Vol. 6, n. 1, Janeiro-Março. 2020

\section{Introdução}

Historicamente os seres humanos desenvolveram diversas formas de ensinar, do modo mais apropriado do conhecimento em que há inspiração nas histórias e práticas cotidianas até a institucionalização da educação por meio das escolas formais. Notamos que a sociedade contemporânea em sua natural construção, caracteriza-se de diversas expressões étnicas e culturais próprias, que refletem significativamente a multiculturalidade no interior das escolas, o que exige conhecimentos específicos dos profissionais envolvidos nos processos educacionais. É na Carta Maior (CF-88), que o artigo 27, inciso I, defende à educação como "a difusão de valores fundamentais no interesse social, aos direitos e deveres dos cidadãos de respeito ao bem comum e a ordem democrática".

E o modo como as formações profissionais desde a graduação vem sendo priorizadas a atender lógica de mercado, e distancia ao mesmo tempo do modelo democrático. Visto mais apropriado às demandas, deveria embasar o desafio das políticas públicas de educação do campo em formar sob as hipóteses e sentidos do lugar e da vida que cada um brasileiro estabelece. Pois, "[...] a educação como formação, como processo de conhecimento, de ensino, de aprendizagem, se tornou ao longo da aventura no mundo dos seres humanos uma conotação de sua natureza, gestando na história" (FREIRE, 2001, p.12). De forma que a educação constitui se em modos diferentes conforme, a diferenças dos povos e dos tempos.

Assim, a constituição desse quadro de gestores nas escolas do campo no Tocantins, demonstra necessidade urgente do estado assumir o papel de garantir subsídios aos gestores no complexo enfrentamento dos velhos paradigmas recorrentes e indicados nesta análise coletiva, a partir da formação e desempenho específicos da função em contextos tão distintos. Brandão (2007) em suas análises acerca da educação como elemento formador do humano nos abre a percepção de que o educar também é moldar sujeitos em consonância com a sociedade em necessidade com as exigências e aspirações do grupo. Tendo a educação como grande amplitude, o autor nos leva a compreender a discussão da educação como meio de formação do sujeito.

A evolução do conhecimento e o estabelecimento de seus novos limites são estabelecidos pelo conflito entre aquilo que está posto e o "novo", desta aproximação, surgem testes, falseamentos e novas sustentações. Novas reflexões e a implementação de novas estruturas de conhecimento tornam mais robustas as construções científicas alinhadas à busca de solução de problemas da sociedade. MORAES, PÔRTO JUNIOR, GILIOLI (2017). Nesse artigo abordaremos suas reais experiências e perspectivas da 


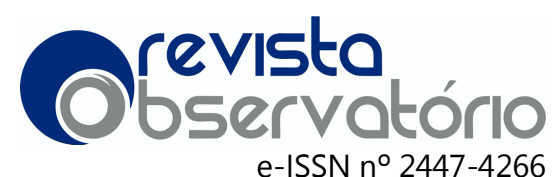

Vol. 6, n. 1, Janeiro-Março. 2020

educação fundamental de relações étnica-raciais, tomando como referência as escolas do campo na Diretoria Regional de Ensino de Dianópolis, numa discussão cerca da contradição vivenciadas em meio à legislação constituída dos direitos dos povos e populações do campo e a marginalização da modalidade de ensino.

O campo brasileiro é bastante diverso. Reconhecendo essa característica, a Resolução 02/2008, do Conselho Nacional de Educação, estabelece diretrizes, normas e princípios para a Educação Básica do Campo, define as populações rurais como: agricultores familiares, extrativistas, pescadores artesanais, ribeirinhos, assentados e acampados da reforma agrária, quilombolas, caiçaras e outros.

De acordo, foram surgindo às nomenclaturas de povos do campo, os processos passaram por várias ressignificações dos pensamentos que chegaram à aproximação das questões ideal de uma política pública de educação que valorizasse a formação, a partir da produção de ciências sobre o exercício prático dos processos educacionais. Que também, mais recente incidem com a decisão do MEC reorientar parcialmente os recursos na rede de escolas técnicas federais, em promoção das formações de qualificação inovadora, mas, que pouco tem a contribuir com o campo, quando não se leva em conta as diferenças socioambientais ali constituídas.

Que segundo Peter Mclaren (2000) apresenta como uma das tendências identificadas do multiculturalismo conservador com a hierarquização dos diferentes grupos étnicos e a supremacia branca com o projeto de uma cultura comum de base eurocêntrica, que deslegitima outras formas de conhecer e aprender os diferentes valores pertencentes aos diferentes grupos subordinados.

Projeto este que prejudicou propositalmente, todo um processo de formação que por muito anos nos levou a crê numa incapacidade forjada pela mente e mão aquela supremacia, hoje contestada cientificamente na veracidade dos fatos perpetrados.

Conforme Sousa e Corrêia (2002, p. 57), apesar da gestão democrática está consagrada como princípio constitucional desde a Carta Magna de 1988 e comparecer também na LDB/96, "[...] essa determinação legal, por si só, não garante uma escola de qualidade e democrática. Esse fato mostra a necessidade de serem empreendidos esforços para a construção de uma escola realmente democrática".

Para superar de vez está demanda da participação coletiva nas escolas públicas, sabemos que para além da integração dos segmentos educacionais, a gestão precisa realizar ações que de fato, garanta espaços para a participação e parceira de toda comunidade escolar, que abrange os responsáveis pelos alunos e inclusive beneficiários indiretos. Mas, também crê, que a questão central para os educadores críticos é ainda, 


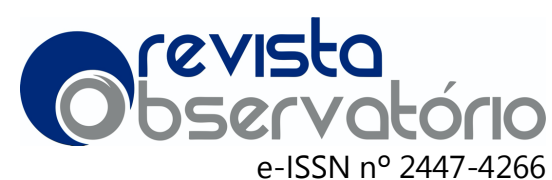

Vol. 6, n. 1, Janeiro-Março. 2020

desenvolver um currículo e uma pedagogia multicultural que se preocupa com a especificidade "em termos de raça, classe, gênero, orientação sexual etc. da diferença" (id. P. 70).

Para tanto, a metodologia adotada na fundamentação histórica/ filosófica desta pesquisa bibliográfica e documental que prevaleceu, junto, às abordagens teóricas metodológicas, com caráter qualitativo e foco empírico dado às categorias centradas na observação de três escolas, tendo como organismo, análise das ações no P.P das mesmas, trabalhos realizados e relatórios.

A convergência interdisciplinar assinala três linhas de análise: a formação de gestores, a política de educação do campo e as abordagens multi/intercultural, como fatores já analisados por outras pesquisas que abordam entorno do desempenho dos profissionais que no exercício da gestão pública escolar, assumem os desafios da adversidade, como a não aplicabilidade devida da política pública, da formação específica e a democratização do ensino de qualidade, como apontam, (MCLAREN, 2000; SOUSA E CORRÊIA 2002; ARROYO, 2012; FREIRE, 2001; BRANDÃO, 2007; GADOTTI, 2003) e outros.

Contudo nesse enfatiza a necessidade de inovar ao tempo que buscam efeitos nas ações desenvolvidas com perspectivas de transformação da própria atuação, no tange construir rompendo com paradoxos estabelecidos diante dos direitos educativos dos estudantes e formativos dos profissionais na educação do campo, que se encontra estagnadas no campo.

Neste âmbito se reconhece a educação como instrumento para contribuir como uma missão emancipatória e crítica, com total participação dos sujeitos sociais, impactados pelos projetos de desenvolvimentos econômicos, pressionando o Estado por outro projeto de campo, de cidade, de sociedade (ARROYO, 2012). Por fim, a pesquisa desenvolvida no campo da educação, pretende demonstrar a imprescindível importância do reconhecimento territorial e das identidades que dar-se em cada escola, para que permita reconhecer o devido valor, aos que constituem este contexto de diferenças e concepções identitárias ainda ignoradas.

Gadotti (2003) e Brandão (2007) desenvolvem em suas discussões acerca do conceito de educação partido do pressuposto de que toda e qualquer sociedade traz intrinsicamente em seu modelo social práticas educativas que visam modelar ou direcionar as ações dos sujeitos que delas participam. 


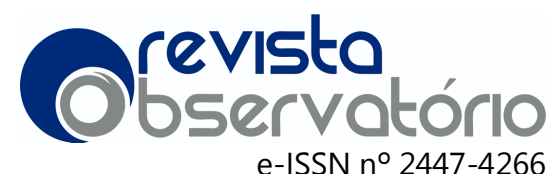

Vol. 6, n. 1, Janeiro-Março. 2020

Os conceitos de educação, formação de gestores, política de educação do campo, multi/intercultural em construção.

A educação ligou-se estreitamente à esperança da libertação social daqueles que obtivessem frutos que a educação promete, configurando uma sociedade aberta e móvel, na qual a hierarquia estabelecida em relação ao binômio educação-profissão substitui as hierarquias devidas à origem social (IMBERNÓN, 1999).

Marx também não via com bons olhos uma educação oferecida pelo Estado-Nação burguês, capitalista, basicamente por desacreditar no currículo que ela traria e na forma como seria ensinado. Mesmo que tenha defendido a educação compulsória em 1869, Marx opunha-se a qualquer currículo baseado em distinções de classe. O que nos remete lembrar, que a luta por uma educação igualitária vem de longos debates.

E assim, a educação brasileira, permitiu que muitas das características marxistas influenciassem nas deliberações que moldaram para este atual modelo- ainda não satisfatório. Contudo, Lemme (1988:213), "argumentou que só algum tempo mais tarde, principalmente, a partir de 1933, influenciado pelos acontecimentos político-sociais que vinham se desenrolando no mundo e no país, é que se interessou mais de perto pelo estudo dessas questões, ou seja, as obras de Marx". Vale lembrar, que as conjunturas do pensamento neoliberal estão povoando a educação nacional e disputam ideologicamente uma nova configuração educacional, especialmente no que diz respeito às políticas de formação profissional.

Concordo com a ideia que treinar com propósitos nos mais adequados padrões e seus subsídios para o processo educacional, não é nada simples, por exige a localização da relação sujeito-objeto como um eixo essencial. A história da filosofia tem demonstrado ser esta preocupação e é um dos principais problemas da filosofia. Assim, compreender a relação sujeito-objeto é compreender como o ser humano se relaciona com o ambiente, com a natureza, em suma, com a vida (GRAMSCI, 1991).

Sabe-se que para além da abrangente falta de estruturas o investimento em programas educativos, nas práticas ou produções sobre formação do educador do campo não tem sido animador, e tem contribuído para a redução de profissionais qualificados na área.

A contecimento que leva a decadência da modalidade, com a redução de escola do campo, elevação dos índices de abandono ou analfabetismo e o agravante êxodo rural. O que caracteriza como inópia das ciências sociais e elementos colocados à disposição para buscar tal formação recomendada ao aprofundamento sobre quais 


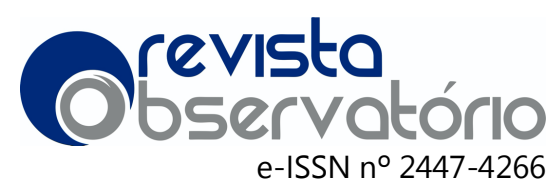

Vol. 6, n. 1, Janeiro-Março. 2020

seriam os saberes indispensáveis no desenvolvimento e capacitação dos servidores da educação do campo.

Que por sua vez, pouco é estimulado os espaços interdisciplinares com caráter emancipatório ou decolonizador os quais surgiram na academia dos Estados Unidos na década de 1960 e no começo dos anos 1970 e que levaram o nome de "estudos étnicos" (BUTLER, 2001; YANG, 2000). Isto inclui os estudos afro-americanos (Black studies, African American studies, African studies), os estudos indígenas (American Indian studies, Native American studies), os estudos ásio-americanos (Asian American studies, Asian diaspora studies), e os estudos focados em comunidades de descendência latino-americana nos Estados Unidos (Latino studies). Étnico não significa simplesmente etnicidade neste contexto. O termo étnico, a bem dizer, expressa o ponto de vista que considera alguns sujeitos como nacionais ou com todo direito de reivindicar cidadania e participação na ordem moderno-ocidental, enquanto relega outros a uma condição na qual sua existência nacional ou sua existência na ordem moderno-ocidental é constantemente questionada.

A interculturalidade é o conjunto dos processos psíquicos, relacionais, grupais, institucionais [...] originados pelas interacções das culturas, numa relação de trocas recíprocas e numa perspectiva de salvaguarda de uma relativa identidade cultural dos parceiros em relação. (CLANET, 1993, p. 21).

Contudo é a provocação e o meio para o surgimento espontâneo da formação de conhecimentos. A noção de interculturalidade implica conceber a cultura numa perspectiva antropológica, como universo de significações particulares a um grupo, sendo importante conceber "[...] a cultura como relação particular ao mundo de um determinado grupo, o que inclui um conjunto de normas, de valores, de modos de vida, de ritos, assim como uma língua que o grupo transmite, elementos que são constitutivos da sua identidade cultural." (CLANET, 1993, p. 108).

Ter conhecimento que a formação de todo gestor muito tem se dado em sua relação com o a comunidade escolar, configura como fator determiante na formação continuada estabelecida por cada profissional, o que tem confiado o estado omisso. $O$ perfil e sua responsabilidade são os aspectos de todo um processo de padronização da política de formação na educação, integrada ao sujeito e à sociedade moderna ocidental. Sustento que o conceito de decolonização epistêmica e, mais amplamente, os conceitos de decolonização do ser, do poder e do saber adicionam precisões importantes para entender as formas de conhecimento com um caráter decolonizador (Torres, p.2). 


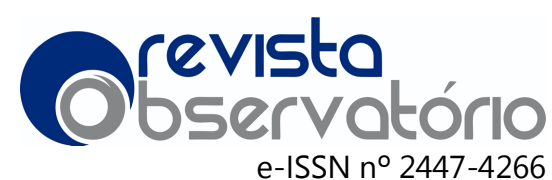

Vol. 6, n. 1, Janeiro-Março. 2020

Para tanto, tais artifícios tornando autênticos na política de educação do campo, o silêncio que sempre foi uma forma de oprimir, justifica-se assim surgir como terreno fértil para formas de ressignificação sobre o que não se adequa a realidade nacional, sobretudo a que se trata dos sujeitos e culturas a serem emancipados. Nesses termos se deu brechas para ser quem realmente são podendo desconstruir os esteriótipos da colonização e saber promover as formas de coletivamente sustentar comunidades tão distintas.

A maioria dos filósofos educacionais, independentes de sua teoria particular, sugere que a solução para os nossos problemas pode ser mais bem alcançada por meio de um pensamento crítico e ponderado sobre a relação entre mudanças perturbadoras e as ideias resistentes (OZMON E CRAVER, 2004).

Identificar e compreender em quais bases pode se fundamentar os processos formativos de educadores comprometidos em acessar o conjunto de saberes diversos, que thes possibilitem "assumir a tarefa educativa em toda sua complexidade, quando reflexivamente com a flexibilidade e rigor necessários" (IMBERNÓN, 2004, p. 60).

Assim, acordada a um componente fundamental, qual seja, a ancestralidade, a dimensão territorial foi reforçada como componente da sustentabilidade do ser humano. A mudança é um processo que vai se construindo aos poucos, de acordo com o nível de desenvolvimento de cada sociedade, como consequência das mudanças de maneiras para suprir suas necessidades, o homem muda também os padrões de cultura no decorrer dos anos, porém: "muda a sociedade e somente mais tarde muda a educação" (LIBÂNEO, 1998:153).

Contudo, essas categorias formação de gestores e educação do campo estam relacionadas com o multicultural presente no contexto quais estam inseridos e são questionadas quando se está diante de experiências que recorrem precisamente a visivelmente garantida pela legislação, às interlocuções, bem como a visível padronização da política de formação. Aquilo que aparentemente estava resolvido passa a ser questionado no que se tangue distinguir que cada sujeito político desta amostra análisada, é dotado de necessidades, e, todavia alternativas específicas.

A política de educação do campo: a formação de gestores, as tendências e as práticas de numa perspectiva multi/intercultural do conhecimento.

Pesquisadores têm discutido o que está evidente nas legislações e documentos orientadores quanto á política de educação do campo - a exemplo a que nas últimas 


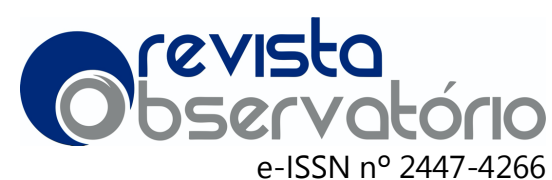

Vol. 6, n. 1, Janeiro-Março. 2020

décadas, uma nova concepção ganha força, gestada pelos próprios sujeitos do campo, organizados nos movimentos sociais de luta pela democratização da terra, preservação das matas e florestas, rios, manguezais e reconhecimento das culturas. Essa concepção é denominada Educação do Campo.

Que foi incorporada nas DCNEl em Básica nas Escolas do Campo (Resolução CNE/CEB n1, 03 de abril de 2002), aprovadas após a emissão do Parecer CNE/CEB 36/2001. Em 2008, foram ainda aprovados o Parecer CNE/CEB 03/2008 e Resolução CNE/CEB 02/2008. Esses documentos são históricos na regulamentação e orientação da educação do campo no país [...].

No conjunto das ações que compuseram a política do governo federal para a educação do campo desde então, um aspecto merece ressalvas, pois foram à abertura as interlocuções a outras instâncias do próprio governo ou como a que se deu com movimento civil.

O Estatuto da Criança e do Adolescente, em seu artigo 58, afirma: "No processo educacional respeitar-se-ão os valores culturais, artísticos e históricos próprios do contexto social da criança e do adolescente, garantindo-se a estes a liberdade de criação e o acesso às fontes de cultura".

Que estimulou a criação da Lei 10.639, sancionada em 10 de janeiro de 2003, alterando posteriormente a Lei de Diretrizes e Bases da Educação Nacional - LDB (Lei Federal 9394/96) em seus artigos 12, 13 e 14 estabelece a participação da família, da comunidade e dos profissionais na elaboração e conhecimento da proposta pedagógica, assim como o Conselho de Escola como parte da gestão democrática. Contudo, é inegável que ocorreu uma eficácia na democratização e acesso as informações. Infelizmente, não tão quanto deveria, considerando que continuaram legitimando esta concepção, ocidental em que:

\footnotetext{
"os multiculturalistas conservadores disfarçam falsamente a igualdade cognitiva de todas as raças e acusam as minorias mal sucedidas de terem bagagem "bagagens culturais inferiores" e a "carência de fortes valores de orientação familiar" (MCLAREN, 2000, p.113).
}

Neste aspecto, os tributos dos povos étnicos são invisibilizados e (ou) reduzidos a "acréscimos" à esta cultura já dominante e fortemente adotada por seus padrões capitalistas, que brevemente sugeriu adotar a tese da diferença e "criar uma política se construção de alianças, de sonhos compartilhados, de solidariedade que avance para 


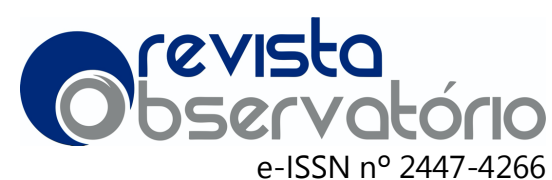

Vol. 6, n. 1, Janeiro-Março. 2020

além de posturas condescendentes (como por exemplo, 'a semana das raças', que na verdade servem para manter as formas de racismo institucionalizado intactas)" (id., 1997, p. 95). Como estão calejados de presenciar tais comportamentos na tão lembrada semana da consciência negra, uma vez por ano.

E que nada adianta ao percebermos, a reincidência das subversões na ação da semana e (ou) logo seguinte, com as mesmas práticas excludentes de preconceito e discriminação, sucedida por quem não tolera, tampouco respeita e reconhece as diferenças da pluralidade raciais, culturais, sociais dentre outras quais situam a multiculturalidade e a interculturalidade, que Catherine Walsh, (2012) traz como sendo efeitos resultantes de ações e movimentos políticos sociais desde os nossos ancestrais que já lutavam por reconhecimento e direitos dos legítimos povos tradicionais. Igualmente reconhecidas pelos interstícios intercambiais, do determinado interculturalismo.

Assim,

A educação intercultural só pode conceber a atenção e o respeito que indivíduos de diferentes culturas merecem se ela for capaz, antes de tudo, de reconhecê-los como seres humanos genéricos, que apresentam uma vocação transcultural para a racionalidade. Só posso respeitar verdadeiramente a alteridade do outro se reconheço essa alteridade como uma outra modalidade possível do humano (FORQUIN, 1993, p.63).

Forquin percebe o interculturalismo como uma disposição que assemelhar-se, vir de encontro à demanda na prática dos gestores que apresentam em suas narrativas profissionais, a confirmação de uma tendência na formação de todo educador, necessariamente apropriar das práticas e saberes ligados as ações da docência.

Em especial, os gestores precisam estar dispostos e atuar ativamente no auxílio das atividades concretizadas pelos professores no dia-a-dia da escola, cuidando para que o currículo esteja em constante interação com o contexto inserido. Técnicas estas, que não se resume em metodologias como "receitas" prontas, mas, com fundamentos utilizados para garantir a efetivação das propostas e previsão da educação básica em meio à diversidade social.

A contemporaneidade dos processos educacionais são fundamentalmente, por sua vez demandas do processo histórico de formação nos cursos de habilitação específica baseada quase sempre na graduação, o que fundamenta a buscar de novos conhecimentos e os desafios políticos e pedagógicos encontrados. 


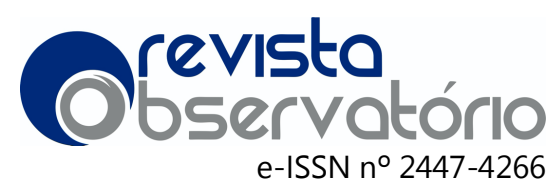

Vol. 6, n. 1, Janeiro-Março. 2020

É nessa perspectiva que, não só Movimento Negro, mas também pesquisadores (as) negros (as) e brancos (as) e alguns políticos engajados na temática vêm se debruçando para garantir a efetiva implementação da referida lei a partir de programas educacionais, cursos de formação continuada de professores e profissionais da educação, debates e seminários, a fim de pensar uma educação para as relações étnicas raciais (SILVIA, 2012.p.75).

O quadro abaixo detalha uma amostra em três linhas, com enfoque nas formações dos gestores educacionais e, consequentemente a leitura, seguida de uma avaliação das evidências.

Quadro 1 Leituras para reflexão sobre seus currículos e mais especificamente nas tendências na Formação de Gestores.

\begin{tabular}{|c|c|c|}
\hline Sequência & Graduações & Pós-graduações \\
\hline 1 & $\begin{array}{l}\text { - Bacharel em Ciências Biológicas; } \\
\text { - } \quad \text { Licenciatura em Geografia e } \\
\text { Pedagogia; }\end{array}$ & $\begin{array}{l}\text { - } \quad \text { Gestão ambiental; } \\
\text { - } \quad \text { Psicopedagogia; }\end{array}$ \\
\hline 2. & $\begin{array}{l}\text { - } \quad \text { Bacharel em Administração; } \\
\text { - } \quad \text { Licenciatura em Normal Superior; }\end{array}$ & $\begin{array}{l}\text { - Tecnologias em Educação } \\
\text { Inclusiva; }\end{array}$ \\
\hline 3. & $\begin{array}{l}\text { - } \quad \text { Bacharel em pedagogia; } \\
\text { - } \quad \text { Licenciatura em Letras } \\
\text { Portuquês/Espanhol: }\end{array}$ & $\begin{array}{l}\text { - Gestão, Orientação e } \\
\text { Supervisão Escolar; }\end{array}$ \\
\hline
\end{tabular}

Fonte: elaborado pela autora.

Analisando inicialmente, far-se-á uma crítica à primeira categoria que aponta como um problema é a formação profissional alinhada em áreas afins - ignorando a presença dos processos interdisciplinares demandados por todas as profissões. Ou seja, quando se determina cursar uma graduação em administração, logo, fará especialização neste mesmo campo correspondente. Numa lógica mercadológica, terás o currículo adequado para assumir a gestão de qualquer empresa, inclusive educacional.

Entretanto, o segundo problema está em perceber que o desempenhar bem da função em gestão educacional, dependerá de formações especificas correspondentes à modalidade que atuará. Se tratando especificamente da educação do campo, conforme dados do INEP, o percentual de profissionais graduados é muito alto. Porém, parte significativa alega não ter recebido nenhuma formação específica.

Nota-se, que a temática de formação é uma das mais evidenciadas por tratar de um fenômeno dominante nos debates entre pesquisadores. É importante, ressaltar a maioria das pesquisas recai sobre docentes, em geral das escolas urbanas. 


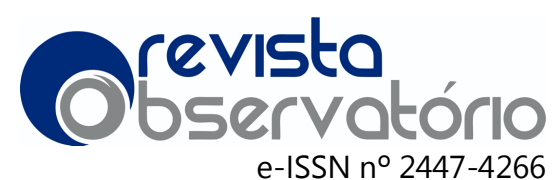

Vol. 6, n. 1, Janeiro-Março. 2020

O quadro a seguir, apresenta textos desenvolvidos a partir das evidencias presentes nos relatórios de atividades que se aplica a questões observadas. Seguido das considerações.

Quadro 2 Leituras para reflexão, das abordagens da teorização e práticas específicas de cada gestor atuante.

\begin{tabular}{|c|c|c|}
\hline Sequência & Observação & Compreensão \\
\hline 7 & $\begin{array}{l}\text { a) A educação do campo vem hoje } \\
\text { sendo executados numa sistemática ou } \\
\text { programa específico? Quais? }\end{array}$ & $\begin{array}{l}\text { Avalia que a modalidade educação } \\
\text { do campo não segue um } \\
\text { programa especifico. Os } \\
\text { assessores têm orientado as } \\
\text { escolas seguir as Diretrizes } \\
\text { Curriculares da Educação do } \\
\text { Campo e a BNCC-(Base Nacional } \\
\text { Comum Curricular). Que enquanto } \\
\text { as formações, tem ocasionado } \\
\text { com frequência, com o incentivo } \\
\text { da implementação da nova e } \\
\text { referida BNCC - qual recentemente } \\
\text { passou por uma reestruturação. }\end{array}$ \\
\hline 2. & $\begin{array}{l}\text { b) A escola tem promovido ações sob } \\
\text { uma perspectiva intercultural? }\end{array}$ & $\begin{array}{l}\text { - Analisa que todos os anos } \\
\text { os PPP propõem a realizar ações } \\
\text { voltadas para a valorização das } \\
\text { minurias, principalmente os } \\
\text { negros, as mulheres, as diversas } \\
\text { expressões religiosas e orientação } \\
\text { sexual. } \\
\text { - Observa sim, que as } \\
\text { escolas realizam ações envolvedo } \\
\text { as diferentes culturas, que } \\
\text { envolvem a comunidade escolar. } \\
\text { A exemplo, podemos citar a } \\
\text { capoeira e a folia. }\end{array}$ \\
\hline 3. & $\begin{array}{l}\text { c) Algum profissional recorda de ter } \\
\text { participado de alguma formação } \\
\text { voltada para a interculturalidade ou } \\
\text { relações etnicarraciais? }\end{array}$ & $\begin{array}{l}\text { - Mencionam ter participado } \\
\text { de várias formações voltadas para } \\
\text { a interdiciplinaridade como prática } \\
\text { cotidiana na sala de aula, } \\
\text { valorização do ser humano } \\
\text { independente de qualquer } \\
\text { realidade a qual esta inserida. } \\
\text { - Em desacordo, outros não. } \\
\text { Lembram até que a escola procura } \\
\text { participar ativamente de todas as } \\
\text { formações e capacitações } \\
\text { pormovidas por essa DRE. Mas, aq } \\
\text { quem nunca participou de } \\
\text { formacões com esta temáica. }\end{array}$ \\
\hline
\end{tabular}

Fonte: elaborado pela autora.

O estudo revela que houve avanços significativos com a reformulação e implementação da atual versão BNCC. Seguida de formações embasadas a partir dos referenciais curriculares, tem alargado os debates e possibilidades de ações no interior 


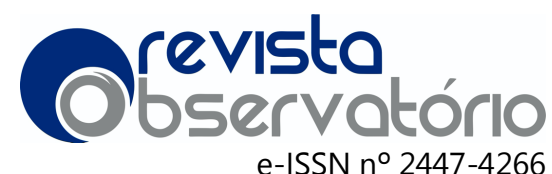

Vol. 6, n. 1, Janeiro-Março. 2020

das escolas de educação do campo, podendo assim, constatar a ampliação da problematização sobre os anseios, que abarcam questões do cotidiano escolar como os processos de formação, ensino e aprendizagem e as relações sociais e interacionais com perspectivas de maior visibilidade as práticas e sujeitos dotados de conhecimentos e saberes comunitários.

E assim, no conjunto deste debate, percebe-se o Processo de Bolonha, que acelera tanto a formação e, possivelmente, as competências e habilidades, quanto o prazo de respostas às indagações construídas sobre demandas da sociedade (PÔRTO JUNIOR, 2017a e2017b). Em especial a circunscrição deste debate ao plano de gestão das organizações tem assumido evidencia dada às novas concepções das relações interinstitucionais desenhadas pela internacionalização de processos negociais, muitas vezes articuladas segundo os interesses de blocos econômicos. Mas, que se nota inconscientemente, sendo adotado para fins das formações educacionais.

Consta nos registros que têm compromisso em pensar nos alunos desde a construção do PPP da escola, qual prevê durante o ano ações que valoriza a subjetividade expressões culturais de cada povo. Percebe-se da necessidade de transformar essas ações em momentos do cotidiano escolar, de modo a contribuir com a densidade da relação com o saber e a escola.

Entre outros, alguns chegaram a mencionar a sua participação em vários momentos de formação voltadas para suas realidades do campo. Porém, houve controvérsias com relação, pois teve quem dissesse nunca ter participado. Ambos afirmam que os encontros de formação realizados pela diretoria, sempre configuram muito proveitosos.

Todavia lembram que um dos problemas desta formação dos gestores está na falta de técnicos profissionais com formação e conhecimentos específicos. Diante da necessidade de investigar e encontrar resposta, quanto às tendências na formação de gestores, pôde-se avançar que, no Brasil, não existe uma cultura profissional específica comum necessária para falar de um ofício de formador para formador, com saberes e competências próprias (LINS, 2007, pp. 135-151). Consequentemente, os mesmos têm aprendido em paralelo com as demandas das formações que ministram.

Em resultado disso é que as instituições pesquisadas apresentam como formadores de formadores o que Shön (2000) chama de "educadores profissionais", ou seja: professores universitários que são responsáveis pela formação específica desses profissionais. Entretanto, Lins (2007) discorre que esse fator não impede que as 


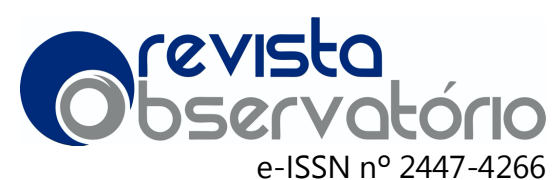

Vol. 6, n. 1, Janeiro-Março. 2020

características educacionais e profissionais levantadas dos acadêmicos pesquisados sinalizem na direção de um "perfil-tipo" de formadores especialistas.

Também há outro problema, que se constitui com as insuficiências do suporte didático-pedagógico, que tornam as aulas menos dinâmicas e mais estáticas. Apesar, de concordarem com a consideração feita por (FISCARELLI, 2007), de que o material didático por si só não é suficiente para a efetivação dos trabalhos realizados em sala de aula e que sua realização exclusiva não é capaz de promover um eficiente processo de ensinoaprendizagem.

Contudo, durante muito tempo, o maior problema causador de lacunas no conhecimento adquirido ao logo da formação e atuação profissional dos educadores, foi das políticas educacionais não reconhecerem os povos do campo como produtores de conhecimento. Nas suas diversidades, os povos da floresta, caiçaras, ribeirinhos, assentados, povos dos interiores eram vistos como meros receptores de propostas elaboradas numa lógica que os submetia a relações de dominação sob os aspectos culturais, ambientais, econômicos, políticos. Consequentemente, o pouco tempo dedicado à carga horária destas formações que, todavia, as organizações nunca tiveram para discutir e atuar com a complexidade das várias expressões da diversidade (quilombolas, negros, indígenas, pessoas com deficiência, povos do campo, população LGBT, dentre outras), tendendo a ressaltar, dentro do grande leque da diversidade, apenas algumas de suas expressões e subalternizando outras.

Estas pesquisas sobre as práticas educativas, as questões levantadas são recorrentes, e vão desencadear em velhas/ novas questões sociopolíticas, se cada um dos envolvidos não buscar promover outras ou mais ações. Como parte do processo as universidades devem urgentemente reformular suas ações no ensino, pesquisa e extensão, com perspectivas de mudanças profundas, que possam favorecer a diversidade étnico-racial, com os programas curriculares de todos os cursos de graduação. Possibilitando-os conhecer a histórica e verdadeira contribuição que os povos tem promovido ao Brasil. E para além, criar condições de legitimar infinitas produções epistemológicas que resultam na resistência de cada segmentos.

Tal reorganização traz consigo a tessitura de novos modelos organizacionais, de novos projetos de processos produtivos e de novos projetos de produtos finais, alinhados aos novos determinantes de mercado, em especial à sustentabilidade que passa pelos campos da ética, do respeito ao meio ambiente e da cooperação à 


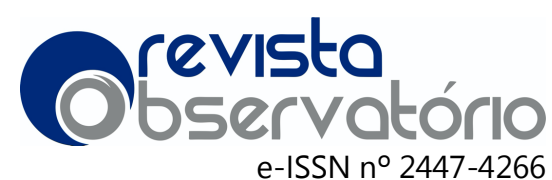

Vol. 6, n. 1, Janeiro-Março. 2020

sustentação de sistemas sociais inclusivos e justos. MORAES, PÔRTO JUNIOR, GILIOLI (2017).

Logo, outra contribuição fundamental é de McLaren na afirmação de se considerar a sala de aula como espaço de narrativas no plural, para que a narrativa única, alicerçada na crença dos conhecimentos universais, seja problematizada. Só assim, se desafiará a branquitude e o eurocentrismo, pois será preciso abrir espaços para as múltiplas narrativas, sejam elas contra- hegemônicas ou não. Como, afirma:

A pedagogia crítica ao tentar oferecer aos professores e pesquisadores um meio de melhor entender o papel que as escolas de fato representam dentro de uma sociedade dividida em raça, classe e gênero; e, neste esforço, os teóricos produziram categorias ou conceitos para questionar as experiências de estudantes, textos, ideologias de professores e aspectos do método escolar, que as análises conservadoras e liberais deixam com frequência inexplorados. (id. 1997, p. 195).

Definição que caracteriza a atitude desses profissionais da gestão educacional, em ousar querer saber quais tem sido suas contribuições e quais serão os futuros desafios para o desenvolvimento da educação do campo? Especialmente, depois de perceber que a resposta para o aperfeiçoamento de sua formação profissional, está de encontro à medida dos seus subsídios com a comunidade escolar. O que pode vir ser compreendido como um método de formação continuada. Isso leva a uma consideração (que não é final), mas, segundo MORAES, PÔRTO JUNIOR, GILIOLI (2017), contribui para o debate acerca dos reflexos de Bolonha à formação profissional alinhada a competitividade que sustenta o campo da gestão ou administração das organizações.

Nesse sentido, Lorrosa (2002, p. 25-26) afirma que: é experiência aquilo que 'nos passa', ou que nos toca, ou que nos acontece, e ao nos passar, nos forma e nos transforma. Somente o sujeito da experiência está, portanto, aberto à sua própria transformação'. Isto é, as coisas que ficaram, que marcaram, e que tocaram nossas vidas são e serão (re)lembradas a todo o momento, e estão explícita e implicitamente presentes no nosso modo de ver, de conceber e de agir sobre o mundo, transformandoo.

O processo de implementação dessa política caminha vagarosamente, e assim cada vez mais há necessidade de ações que envolva profissionais de todas as áreas, num esforço de mostrar amplitude do legado étnico para a diversidade brasileira. A buscar na tentativa de consolidar as relações com as mesmas compreensões e interesses ambientais e sociais do campo, precisa de fato acontecer cogitando os múltiplos autores. 


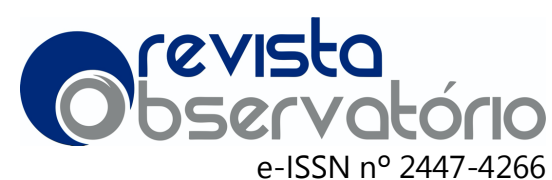

Vol. 6, n. 1, Janeiro-Março. 2020

Segundo Wallon (1979) "o homem é geneticamente social, ele se desenvolve é pelo social". Que necessita debater e estabelecer, a retirar-se dos conhecimentos acumulados por quem conhece ou mesmo possa vir conhecer as crianças do campo e suas perspectivas. Com uma abordagem semelhante, Robert Jeffcoate (apud Forquin, 1993) distingue o multiculturalismo:

Como objeto de estudo ou domínio de intervenção, e como conjunto de dispositivo político ou pedagógico, tendo por meta tanto melhora a situação escolar das crianças das minorias étnicas quanto preparar todos alunos, independente da composição étnica de suas escolas ou de seus bairros, para viver numa sociedade multi-étnica, o que implica, é claro, que este ensino se dirija todos, e não somente aos alunos oriundos de minorias étnicas ou habitantes de bairros de população heterogênea (id. p. 138).

Nessa construção, traz explicito o princípio básico de quem se forma, e assume a função de ensinar. Compreendendo que para atender ao direito da educação do campo. É imprescindível propor criar alternativas de vivência por meio da realidade particular incluindo as diversidades localizadas no território brasileiro.

\section{Considerações finais:}

As ponderações apresentadas nesse artigo buscaram interpretar a contemporânea centralidade na atuação dos gestores educacionais, por meio estratégicos da formação técnica, com o enfoque na regularização estatal das políticas públicas de educação, onde o estado assegura a influência da formação dos individuos envolvidos mediante a imposição da teorização dos conteúdos e as estimativas dos efeitos no ensino e aprendizagem dos processos educacionais, entregues aos interesses do terceiro setor. Diante da inexistência da inovação ou tentativa de suprir as lacunas já existentes no ensino. Pois, o gorverno não assumirá as restrições que possa estabelecer o agravamento da situação atual, tampouco, financiar as estruturas de organização e processos educacionais demandados pela educação do campo.

Poderíamos mencionar ainda infinitas ações a exemplos da desestruturação diária na educação brasileira, conquistada com muita luta. Mas, aqui nos limitamos na revelação quanto às perspectivas de transformações da gestão, que ficarão à mercê da velada autonomia. Considerando, que as escolas, as redes de ensino e as universidades tornaram incapazes de ousar enfrentamentos com propósito de valorizar os profissionais da educação, quando já está em curso as reformas administrativa e da previdência. 


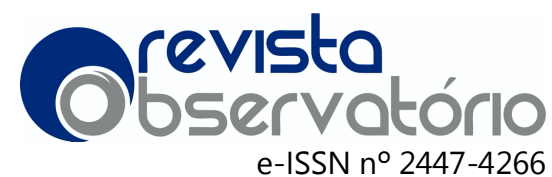

Vol. 6, n. 1, Janeiro-Março. 2020

De modo que, a histórica improvisação nas formações tende a seguir, estes modelos anacrônicos, desconsiderando ou até mesmo reformulando as estruturas legais constituídas através das buscas e resistências de muitos profissionais organizados ao movimento civil, pela a incidência da política pública de educação do campo. Que ainda se encontra fragilizada em razão da marginalização da modalidade, por falta dos devidos investimentos.

Entretanto, até que tudo isso continue, é imprescindível que os educadores se comprometam com esta sociedade que vive em construção, assumindo emergencialmente, a edificação das básicas condições para a continuidade do ensino fundamental no campo. Assim, oportunizando a participação da comunidade escolar, ao adotar as práticas em consonância como a realidade, neste modelo que incentiva o engajamento em regime de colaboração com as organizações do estado, município e sociedade, em articulações intersetoriais de políticas específica inspirado na educação libertadora, no pensamento de Paulo Freire.

Em garantia dos direitos educacionais, assegurados pela Constituição de 1988, a LDB/96 e a Resolução 02/2008, do Conselho Nacional de Educação, compostos por direcionamentos, regras e princípios para a Educação Básica do Campo, a constituir um progresso na superação da percepção hegemônica a propósito da uniformidade dos procedimentos de uso e ocupação do espaço escolar.

A sala de aula, para McLaren, é, portanto, um local de socialização, de encontro, um espaço de múltiplas narrativas de construção, transformação e empoderamento não podendo ser reduzida a um espaço exclusivamente de instrução. Certamente esta é uma das grandes contribuições da pedagogia crítica por ele proposta.

A educação multicultural na perspectiva da pedagogia crítica opõe-se veemente à persistência das desigualdades de raça, gênero e classe. E para isso é necessário, "desenvolver uma práxis dialética que permita fazer uma relação entre a vida cotidiana e esses processos de globalização. Também devem ser capazes de auxiliar os alunos a ver essa dialética e tornar-se pesquisadores desse cotidiano" (McLaren, 2000c, p. 2).

Com base nas ideias de Marx, pode-se concluir que educar é um desafio social. Portanto, esta prática pode tornar-se uma ferramenta articuladora na conjuntura que vive a comunidade, produzida pela não neutralidade da educação e o seu estilo de representação e expedição da cultura hegemônica, que recusam e invisibilizam tantas outras vivências. 


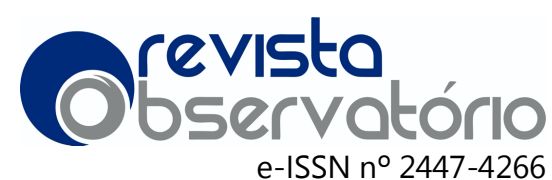

Vol. 6, n. 1, Janeiro-Março. 2020

Para Candau (2011) essa é a direção que deverá ser seguida pra a concretização de uma escola democrática e justa, no sentido de promover a igualdade sem negar a diferença. A autora considera que:

[...] a dimensão cultural é intrínseca aos processos pedagógicos, "está no chão da escola" e potência de processos de aprendizagem mais significativos e produtivos, na medida em que reconhece e valoriza a cada um dos sujeitos neles implicados, combate todas as formas de silenciamento, invisibilização e/ ou inferiorização de determinados sujeitos socioculturais, favorecendo a construção de identidades culturais abertas a sujeitos de direitos, assim como a valorização do outro, do diferente, e o diálogo intercultural. (CANDAU, 2011, p. 253).

Constatou-se, por fim, que não basta proceder esta educação com procedimentos que venham conheçer, análisar e compreender a existência dos povos do campo e suas artemanhas; as preocupações e demandas expressão muito, além disso. Implica ainda mais na sensibilização pelo reconhecimento dos direitos e na corresposabilidade de participar diretamente da execução das políticas específicas, além de abranger a outra proposta. Que trata-se do imprescindível conhecimento e aplicabiliade do que Edgar Morin, que prever impactar o pensamento e adaptação humana, sobre a ideia de educação, que poderá implicar na relação de poder com a sociedade.

\section{Referências}

ARROYO, Miguel G. Outros Sujeitos, Outras Pedagogias. Petrópolis RJ: Vozes, 2012.

BRANDÃO, Carlos Rodrigues. O que é educação. 1 ed. São Paulo: Brasiliense, 2007.

BRASIL. Constituição (1988). Constituição da República Federativa do Brasil: Brasília: Senado federal, $1988 . \quad$ Disponível em: $<$ http://www.senado.gov.br/sf/legislacao/const/>. Lei No. 9.394/1996. LDB - Lei de Diretrizes e Base da Educação Nacional, Senado Federal. Secretaria Especial de Editoração e Publicações. Brasilia-DF, 2007. Ministério da Educação. Secretária Especial de Políticas de Promoção da Igualdade Racial. Diretrizes Curriculares Nacionais para a Educação das Relações Étnico - Raciais e para o Ensino de História e Cultura Afro - Brasileira e Africana. Brasília, 2004.

BUTLER, Johnella (Ed.) Color-line to bonderlands: the matrix of American ethnic studies. Seatlle: University of Washington Press, 2001.

CANDAU, V. M. Diferenças culturais, cotidiano escolar e a práticas pedagógicas. Currículo sem Fronteiras, v.11, n. 2, p. 240-255, 2011. 


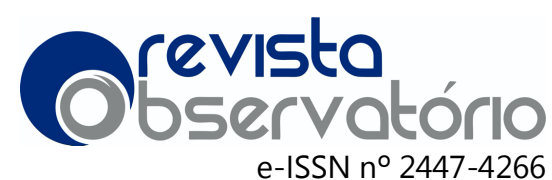

Vol. 6, n. 1, Janeiro-Março. 2020

CATHERINE, Walsh. Interculturalidad y (de)colonialidad: Perspectivas críticas y políticas.

Visão Global, Joaçaba, v. 15, n. 1-2, jan./dez. 2012.

CLANET, Claude. L'interculturel. Introduction aux approches interculturelles en education et en sciences humaines. Toulouse: Presses Universitaires du Mirail, 1993.

FISCARELLI, Rosilene Batista de Oliveira. Material Didático e Prática Docente. Revista Ibero-americano em Educação, 2007. v.2, n.1.

FORQUIN, J. Escola e cultura: As bases sociais e epistemológicas do conhecimento escolar. Porto Alegre: Artes Médicas,1993.

FREIRE, Paulo. Pedagogia e Educação: ensaios . 5. Ed. São Paulo: Cortez, 2001.

GADOTTI, Moacir. História das ideias pedagógicas. 8. ed. Ática: São Paulo: 2003.

GRAMSCI, Antonio. A concepção dialética da história. Rio de Janeiro: Civilização Brasileira, 1991.

IMBERNÓN, F. (1994). La formación y el desarrollo profesional del profesorado. Hacia una nueva cultura profesional. Barcelona, Graó.

IMBERNÓN, Francisco (org.). A educação no século XXI. Os desafios do futuro imediato. Editora Grão, 1999.

YANG, Philip Q. Ethnic studies: issues and approaches. Albany: State University of New York Press, 2000.

LEMME, Paschoal. Memórias. São Paulo, Cortez / Brasília, INEP, v.2, 1988.

LIBÂNEO, José Carlos. Pedagogia e pedagogos, para quê? São Paulo: Cortez, 1998.

LINS. T. Formador de formador: características educacionais e profissionais de acadêmicos que ensinam na formação continuada stricto sensu em Gerontologia no Brasil. Revista Kairós, São Paulo, 10(2), dez. 2007, pp. 135-151.

LORROSA, J.Notas sobre experiências e o saber da experiência. Tradução: João Wanderley Geraldi. Revista brasileira de Eduacação -ANPED, n.19,Jan./ Fev./ Mar./ Abr., 2002.

MARX, K. O Capital. 8.ed. São Paulo: Difel, 1982. Livro 1, v.1. (1.ed., 1867) SMITH, A. An Inquiry into the Nature and Causes of the Wealth of Nations. 5.ed. London: Methuen and Co./Edwin Cannan, 1904. (1.ed., 1776).

MCLAREN, Peter. Multiculturalismo revolucionário: pedagogia do discenso para o novo milênio. (trad.) Márcia Morais e Roberto Cataldo. Porto Alegre: Artes Médicas Sul, 2000. 


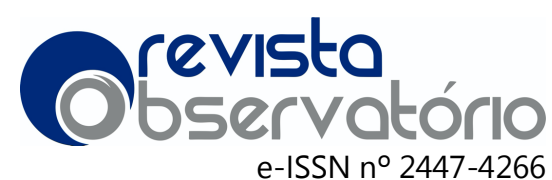

Vol. 6, n. 1, Janeiro-Março. 2020

Pedagogia revolucionária em tempos de pós-revolucionários: repensar a economia política da educação crítica. In: IMBERNÓN, F. (org.) A educação no século. Porto Alegre: ArtMed, 2000c, p.135 -137.

MORAN,E.F. Adaptabilidade humana. São Paulo: Edusp, 1994.

MORAES , N. R., PÔRTO JUNIOR, F.G.R. E GILIOLI, S.N. .CONHECIMENTO E ORGANIZAÇÃO: indicativos pós-Bolonha de uma sociedade em construção. v. 3 n. 6 (2017): V. 3 N. 6 (2017). Dossiê Temático: Processos formativos, comunicação e educação pós-Bolonha Out-Dez 2017.

OZMON, Howard A.; CRAVER, Samuel M. Fundamentos filosóficos da educação. 6. ed. Porto Alegre: Artimed, 2004.

PÔRTO JUNIOR, Francisco Gilson Rebouças. Processo de Bolonha e Formação: estudos e ensaios. Alemanha: NEA-Novas Edições Acadêmicas, 2017a.

PÔRTO JUNIOR, Francisco Gilson Rebouças. Processo de Bolonha: história, formação e ensino na União Europeia. Porto Alegre: Editora Fi, 2017b.

SHÖN, D. A. (2000). Educando o profissional reflexivo. Porto Alegre, Artes Médicas Sul.

SILVA, Paula Janaína. O papel da formação continuada de professores (as) para a educação das relações raciais. Brasília, 2012.

SOUSA, J.V; CORRÊIA, J. Projeto Pedagógico: a autonomia construída no cotidiano da escola. In: DAVIS C. (el al). Gestão da escola: desafios a enfrentar. Rio de Janeiro: DP\&A, 2002. P. 47-75.

TORRES' Nelson M: Transdisciplinaridade e decolonialidade. Tradução de Juarez Bernardino-Costa. (P.2)

WALLON, H. Psicologia e Educação da Criança. Lisboa: Edições 70, 1979. 


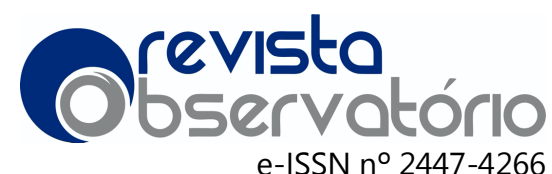

Vol. 6, n. 1, Janeiro-Março. 2020

\begin{abstract}
:
The research presents thoughts on certain trends in the training of educational managers and the needs for innovation to seek to fill the gaps related to basic education. These have been demanded under the panorama of the characteristic reality of rural education: the construction of demands in the fundamental education policy and its perspectives for transformations in the management itself. With the theoretical methodological mention of a bibliographic and documentary research, we sought historical and philosophical foundations for the integration of the categories worked and the empirical focus established in state schools in the Regional of Dianópolis, to delimit the field of the same, which according to the approach, the alternatives have been to seek to carry out self-training actions, simultaneously with the organization of practices in educational institutions. What has made possible a partial exercise of the curricular instrument, when contemplating an education that thinks with cultural diversities and ethnic-racial relations, seeking through experiences and dialogues, to appreciate and adopt community knowledge with the valorization of subjectivity in the ways of each community, showing them in the school routine. The contradiction between the legislation and the educational marginalization, shows the insufficiency in the applicability of education in the field, however, it is important to highlight the urgency in the reformulation of the policy of continuing education for managers, it is proposed to transdisciplinary.
\end{abstract}

KEYWORDS: Training of managers; public policy; rural education and ethnic-racial relations.

\section{RESUMEN:}

La investigación presenta reflexiones sobre determinadas tendencias en la formación de gestores educativos y las necesidades de innovación para buscar cubrir los vacíos relacionados con la educación básica. Estos han sido demandados bajo el panorama de la realidad característica de la educación rural: la construcción de las demandas en la política educativa fundamental y sus perspectivas de transformaciones en la propia gestión. Con la mención teórica metodológica de una investigación bibliográfica y documental, se buscó fundamentos históricos y filosóficos para la integración de las categorías trabajadas y el enfoque empírico establecido en las escuelas públicas de la Regional de Dianópolis, para delimitar el campo de las mismas, que según el enfoque, las alternativas han sido buscar la realización de acciones de autoformación, simultáneamente con la organización de prácticas en las instituciones educativas. Lo que ha hecho posible un ejercicio parcial del instrumento curricular, al contemplar una educación que piensa con las diversidades culturales y las relaciones étnico-raciales, buscando a través de experiencias y diálogos, apreciar y adoptar el conocimiento comunitario con la valorización de la subjetividad en los caminos de cada comunidad. , mostrándolos en la rutina escolar. La contradicción entre la legislación y la marginación educativa, muestra la insuficiencia en la aplicabilidad de la educación en el campo, sin embargo, es importante resaltar la urgencia en la reformulación de la política de educación continua para directivos, se propone transdisciplinar.

PALABRAS-CLAVES: Formación de directivos; política pública; educación rural y relaciones étnico-raciales. 